\title{
Rancang Bangun Peta Interaktif Tiga Dimensi Monitoring Lahan (Monlah) di Institut Teknologi Sepuluh Nopember
}

\author{
Ramadhan Erry P., Febriliyan Samopa, dan Amna Shifa Nisafani \\ Departemen Sistem Informasi, Fakultas Teknologi Informasi, Institut Teknologi Sepuluh Nopember (ITS) \\ e-mail: amnashifia@its-sby.edu
}

\begin{abstract}
Abstrak - ITS menerapkan eco campus yang artinya kampus yang peduli dan berbudaya lingkungan serta telah melakukan pengelolaan lingkungan secara sistematis dan berkesinambungan. Program ITS Eco-Campus memiliki beberapa fokus, salah satunya adalah Program Penghijauan Hutan Kampus Terpadu. Akan tetapi, terdapat beberapa masalah yang dihadapi ITS dalam penerapannya, seperti tidak adanya peta lahan di ITS dan sulitnya memantau pengolahan lahan. Oleh karena itu diperlukan sebuah alat yang berguna untuk memantau lahan, salah satunya dengan menggunakan peta 3D pada lahan ITS. Pembuatan peta 3D lahan ini dibuat dengan menggunakan unity engine. Kemudian, hasil peta 3D tersebut akan dimuat ke dalam sebuah web dan dapat diatur keadaannya secara real-time. Diharapkan dengan pembuatan peta 3D lahan tersebut ITS ini dapat memonitor lahannya dengan baik dan mudah
\end{abstract}

Kata Kunci-Eco-campus, Lahan ITS, Peta 3D, Unity.

\section{PENDAHULUAN}

$I_{p}^{\mathrm{T}}$ (Institut Teknologi Sepuluh Nopember) memiliki program eco campus. Menurut EAUC (Environmental Association for Universities and Colleges), Eco campus merupakan Sistem Manajemen Lingkungan Nasional (EMS) dan bentuk penghargaan untuk sektor pendidikan perguruan tinggi [1]. Skema/pola penghargaan tersebut memungkinkan perguruan tinggi untuk diakui menangani kunci permasalahan dari keberlanjutan lingkungan (environmental sustainability). Program ini diterapkan oleh Institut Teknologi Sepuluh Nopember (ITS) untuk meningkatkan kesadaran serta kepedulian civitas kampus dalam berpartisipasi dalam hal pelestarian lingkungan.

Program ITS Eco-Campus memiliki beberapa fokus, diantaranya adalah 1) Program Evaluasi dan Revitalisasi Masterplan ITS berbasis eco campus, 2) Program Socio Engineering - Implementasi Eco-Campus Terpadu, 3) Program Sistim Pergerakan Internal yang Aman, Nyaman, Sehat, Manusiawi, 4) Program Peningkatan Efisiensi Pemakaian dan Kualitas Air, 5) Program Peningkatan Efisiensi Energi Listrik, 6) Program Pengelolaan Sampah Terpadu, 7) Program Penghijauan Hutan Kampus Terpadu, dan 8) Program Pembuatan Wahana Transportasi Internal Kampus Ramah Lingkungan. Dari semua program eco campus tersebut, yang akan menjadi fokus dalam penelitian kajian ini adalah Program ke-7 yaitu Program Penghijauan Hutan Kampus Terpadu.

ITS memiliki luas lahan sebanyak $1.720 .000 \mathrm{~m} 2$ [2]. Lahan tersebut ada yang berisibangunan diatasnya dan ad a yang tidak memiliki bangunan diatasnya. Dari lahan kosong tersebut akan dijadikan tempat untuk Program Penghijauan Hutan Kampus Terpadu. Karena luas lahan yang dimiliki oleh ITS terlalu luas, sehingga menyulitkan dalam menjalankan programnya. Adapun masalah yang dihadapi ITS adalah sebagaiberikut :

1) Tidak adanya peta lahan di ITS.

Sampai sekarang ITS masih belum memiliki peta yang menggambarkan lahan yang dapat dijadikan patokan dalam menjalankan program penghijauan ITS. Dengan tidak adanya peta lahan ITS mengakibatkan ITS tidak dapat mengetahui fungsi maupun keadaan dari lahan tersebut, apakah lahan tersebut sedang dipakai dalam pengerjaan proyek bangunan, masih menjadi lahan kosong, rawa atau bahkan sudah digunakan oleh masyarakat sekitar ITS untukberkebun.

2) Sulitnya memonitoring pengolahan lahan.

Selama ini setiap ada program penghijauan kampus seperti gugur gunung hasilnya masih sulit untuk dimonitor. Pemantauan penghijauan kampus meliputi lahan mana yang dipakai, tanaman apa yang ditanam, akapan penanamannya, serta pertumbuhan akan tanaman tersebut yang menyulitkan karena tidak adanya dokumentasi. Karena masih kurangnya penanganan lahan di ITS, perlu dibuat patokan-patokan lahan ITS agar ITS dapat mengelola lahan yang terlupakan tersebut dengan baik.

Dari kekurangan tersebut diperlukan suatu alat pemantauan kondisi lahan. Disini peneliti membangun alat serupa yang dinamakan Monlah. Salah satu fitur yang dimiliki Monlah yaitu peta 3D yang nantinya akan menampilkan denah ITS secara keseluruhan. Peta yang akan dibangun oleh peneliti memiliki fitur Virtual Reality (VR). Virtual Reality merupakan konsep teknologi yang dapat memungkinkan seseorang untuk merasakan atau menikmati suasana suatu tempat tanpa harus secara langsung berada pada tempat ters ebut.

Dengan menggunakan konsep Virtual Reality ini, penulis bertujuan untuk membuat peta interaktif tiga dimensi dengan obyek lahan di ITS. Dengan demikian diharapkan pemanfaatan lahan di ITS dapat dijalankan dengan maksimal.

\section{TINJAUAN PUSTAKA}

\section{A. Eco-campus}

Badan Lingkungan Hidup (BLH) Surabaya mendefinisikan eco-campus sebagai kampus yang peduli dan berbudaya lingkungan serta telah melakukan pengelolaan lingkungan 
secara sistematis dan berkesinambungan [2]. Pada program ini ITS turut berpartisipasi dalam pengembangan ilmu dan teknologi serta penerapan gaya hidup yang berwawasan lingkungan. Bentuk nyata dari ITS dalam menjalankan ecocampus ialah dengan membuat program-program, website, slogan, logo yang disebarkan ke civitas akademik ITS. Program-program yang dibuat antara lain :

a. Program Gugur Gunung (G2) ITS (Bersih Kampus dan Penghijauan Massal Berkesinambungan.

b. Penanaman Hutan Kampus (Ruang Terbuka Hijau) berdasarkan fungsi: Konservasi, Budidaya, Pengembangan.

c. Peremajaan pohon/tanaman.

d. Penanaman pembatas lahan ITS/border dengan tanaman yang massive.

e. Penyemaian tanaman/nursery untuk kampus ITS.

f. Pengembangan Live Laboratory untuk rencana Kompleks Diklat ITS Buncitan.

\section{B. Peta Tiga Dimensi}

Peta merupakan suatu bentuk dokumen yang berisikan informasi tentang letak tanah, laut dan gunung di muka bumi, yang berbentuk gambar atau lukisan serta dapat juga disebut dengan representasisuatu daerah [3].

Tiga dimensi yang biasa disingkat 3D atau disebut juga ruang adalah suatu bentuk yang memiliki panjang, lebar, dan tinggi. Saat ini objek tiga dimensi dapat dibentuk dalam lingkungan virtual atau maya yang tidak dapat disentuh secara langsung [4].

Peta tiga dimensi merupakan peta yang digambarkan atau dibuat dengan mengadopsi ketentuan yang berlaku dari objek secara tiga dimensi. Dimana informasi yang ada akan ditampilkan dengan bentuk tiga dimensi. Dan informasi yang akan ditampilkan sesuaidengan kondisidan keadaan nyata dari tempat dan lokasi tersebut.

\section{Unity Game Engine}

Unity3D Engine merupakan salah satu teknologi yang dibuat oleh Unity Technologies yang digunakan untuk membangun tidak hanya sebuah game, melainkan juga suara, teksture, animasi 3D secara real-time dan lain sebagainya [5]. Yang sangat membedakan unity dengan game engine lain salah satunya multi-platfrom dan mudah dikembangkan.

Dalam unity terdapat pilihan bahasa pemrograman untuk mengembangkan game, contohnya JavaScript, C\#, dan BooScript. Tetapi, kebanyakan developer menggunakan JavaScript dan C\# sebagai bahasa yang digunakan untuk mengembangkan game mereka.

Unity3d engine ini memiliki lisensi source proprietary, tapi untuk lisensi pengembangan ada 2 bagian yaitu lisensi gratis dan berbayar sesuai dengan kebutuhan pengembangan pengguna dengan lisensi gratis akan dibatasi pada beberapa fitur atau modul yang biasa tersedia hanya untuk pengguna lisensi berbayar.

Pada Unity game engine memiliki arsitektur seperti Gambar 1 Arsitektur Unity. Dimana pada suatu game terdapat sebuah scenes dan assests yang berada pada level yang sama. Scenes memiliki level dibawahnya yaitu game objek dan komponen.
Assets merupakan sebuah bentuk data yang akan dimasukkan ke dalam game. Scenes merupakan letak atau tempat penempatan sebuah asset yang akan dimasukkan. kumpulan asset dapat juga disebut dengan game objek. Sedangkan komponen merupakan sifat yang akan dimasukkan ke dalam game objek/ assets.

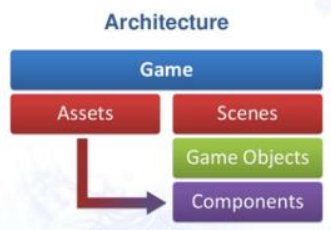

Gambar 1. Arsitektur Unity

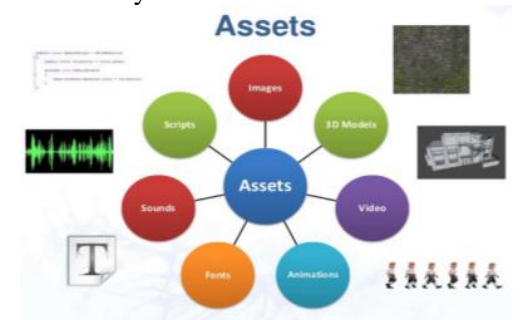

Gambar 2. Assets Unity

\section{Lahan ITS}

ITS memiliki lahan seluas 172 Ha yang dimana pada lahan tersebut ada yang memiliki bangunan di atasnya maupun yang belum ataupun sengaja tidak memiliki bangunan di atasnya. Lahan sebesaritu telah berkurang dikarenakan PENS dan PPNS yang dahulu menjadi satu dengan ITS sekarang telah berdiri sendiri.

ITS memiliki rencana pembangunan kedepannya yang sudah diatur sesuai dengan master plan. Master plan sementara sudah diwakili oleh maket yang berada pada gedung rektorat ITS. Penelitian ini juga bertujuan untuk memantau perubahan yang terjadi pada lahan saat ini dan akan membandingkannya dengan master plan kedepannya.

ITS memiliki rencana pembuatan hutan kampus yang kelola oleh eco-campus. Hutan kampus tersebut berada pada tahap penelitian dalam penentuan pohon yang cocok untuk ditanam sesuai dengan tingkat kesuburan tanah. Denah hutan kampus yang akan dipakai dapat dilihat pada Gambar 3 Peta Masterplan ITS [6].

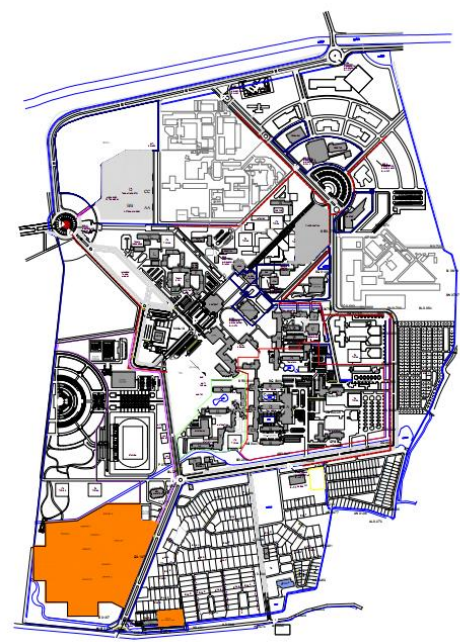

Gambar 2. Peta Masterplan ITS 


\section{METODOLOGI PENELITIAN}

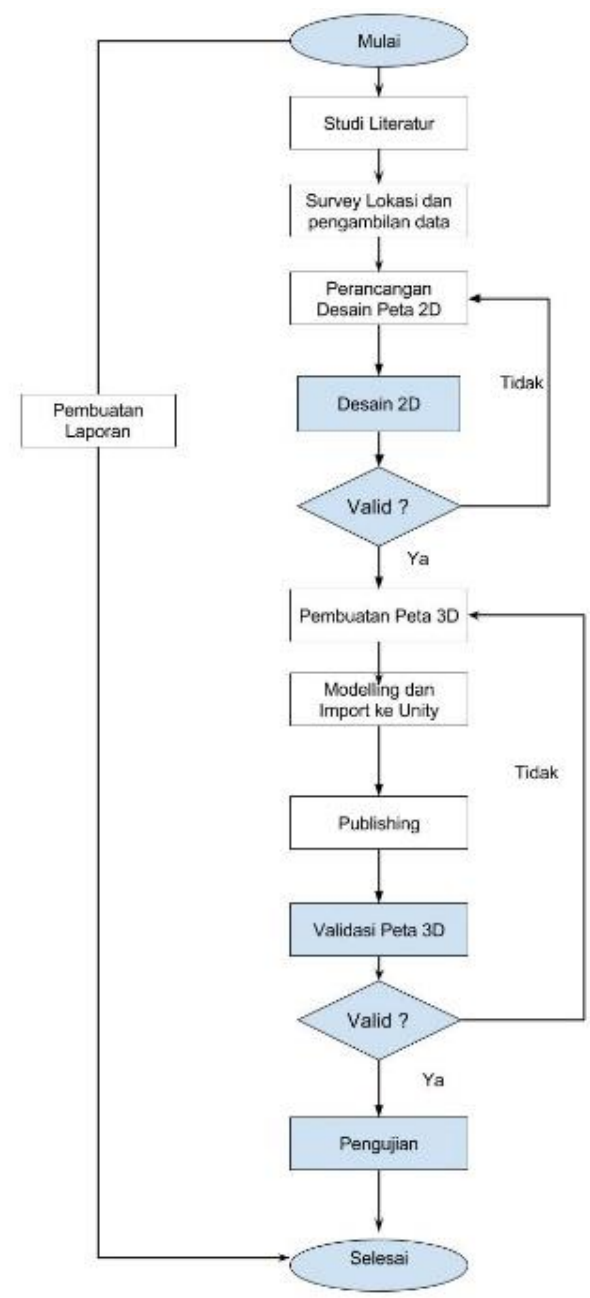

Gambar 4. Metodologi Penelitian.

\section{A. Studi Literatur}

Pada Gambar 4, Tahapan ini dilakukan untukmenggali lebih banyak informasi yang berkaitan dengan masalah yang ada. Informasi yang dimaksud seperti cara mengoperasikan unity game engine dan memanfaatannya agar menjadi peta dan juga penggunaan perangkat lainnya yang mendukung aplikasi serta sinkronis asi antara unity game engi dengan perangkat lainnya.

\section{B. Survey lokasi dan pengambilan data}

Dalam tahap ini peneliti mengambil data berupa foto-foto keseluruhan area dengan maksud untuk meningkatkan akurasi peta dengan keadaan nyata. Data yang diambil mengenai data bentuk lahan dan objek - objek yang akan divisualisasikan ke dalam peta $3 \mathrm{D}$.

\section{Perancangan dan pendesainan peta $2 D$}

Dalam tahap ini peneliti mengambil data berupa foto-foto keseluruhan area dengan maksud untuk meningkatkan akurasi peta dengan keadaan nyata. Data yang diambil mengenai data bentuk lahan dan objek - objek yang akan divisualisasikan ke dalam peta $3 \mathrm{D}$.

\section{Pembuatan peta $3 D$}

Setelah mendapatkan gambaran awal dari rancangan peta, peneliti membuat peta 3D melalui referensi yang telah disepakati. Setelah itu akan membuat model 3D dengan aplikasi modelling seperti Blender atau Sketch Up. Setelah itu hasil model tersebut akan diekspor ke dalam unity. Peneliti membuat peta lingkungan lahan secara 3D dengan memperhatikan kondisi tanah yang menyerupai kondisi lahan.

\section{E. Modeling dan import ke unity}

Dengan menggunakan perangkat 3D designer (Blender/Sketch Up) peneliti membuat dan memasukkan objek vegetasiberbentuk3D yang nantinya akan dimasukkan sebagai pendukung pada peta lahan. Setelah objek pendukung yang berupa vegetasi selesai dibuat, langkah selanjutnya ialah dengan memasukkan objek tersebut ke dalam program unity.

\section{F. Publishing}

Setelah semua dapat berjalan dengan baik, terdapat langkah terakhir dalam pembuatan peta 3D, yaitu mempublikasikan peta 3D yang telah dibuat dan dapat diubah sesuai dengan masukan dari aplikasi sistem informasi pengelolaan lahan.

\section{G. Validasi Data}

Dalam tahap ini peneliti mengecek hasil pembuatan peta 3D dan mencari tahu lagi jika peta masih memiliki kekurangan dan apa saja yang bisa ditambahkan. Jika masih terdapat kekurangan, maka akan dilakukan survey dan pembuatan peta secara ulang.

\section{H. Test dan Evaluasi}

Dalam tahapan ini dilakukan pengujian terhadap peta lahan yang telah dibuat. Tahap ini meliputi apakah fungsi streaming yang digunakan berjalan lancar atau tidak, apakah data yang berasal dari program MONLAH telah tervisualisasi dengan baik. Apabila terdapat fungsi yang belum berjalan dengan baik ,maka tahap pembuatan 3D akan diulang kembali

\section{Pembuatan Laporan}

Pada tahap ini dilakukan proses dokumentasi dari setiap langkah - langkah pengerjaan studidari awal sampai akhir dan ditulis dalam format studihingga menghasilkan buku studi

\section{RANCANGAN PENELITIAN}

\section{A. Analisis Kebutuhan Sistem}

Dalam perancangan desain aplikasi, perlu dilakukan analisis terlebih dahulu agar dapat ditemukan beberapa kebutuhan y ang akan dispesifikasikan sebagai kebutuhan fungsional dan nonfungsional.

Kebutuhan fungsionalitas aplikasi didefinisikan sebagai:

- Melihat peta tiga dimensi (3D).

- Melihat peta dua dimensi (2D).

- Mengubah kualitas tampilan.

- Menghubungkan aplikasi dengan website MONLAH

Kebutuhan non fungsionalitas didefinisikan sebagai berikut:

- Aplikasi dapat diakses di beberapa web browser.

- Aplikasi dapat diakses di beberapa platform OS.

- Aplikasi dapat berjalan dengan lancar

\section{B. Interaksi}

Terdapat beberapa interaksi yang harus ada pada setiap peta tiga dimensi interaktif yang dibuat. 
Tabel 1.

Interkasi

\begin{tabular}{|c|c|c|}
\hline "No. & Interaksi & "Deskripsi \\
\hline 1. & Informasi tempat & $\begin{array}{l}\text { Pada setiap lahan yang memiliki } \\
\text { interaksi terdapat penjelasan singkat } \\
\text { dari lahan tersebut }\end{array}$ \\
\hline 2. & $\begin{array}{l}\text { Menampilkan/ } \\
\text { menyembunyikan } \\
\text { minimap. }\end{array}$ & $\begin{array}{l}\text { Menampilkan at au menyembunyikan } \\
\text { peta overlay peta } 2 \mathrm{D} \text { dan lokasi } \\
\text { karakter pada peta }\end{array}$ \\
\hline 3. & $\begin{array}{l}\text { Mengatur kecepatan } \\
\text { performa saat menjelajah }\end{array}$ & $\begin{array}{l}\text { Membuat pengaturan yang sesuai } \\
\text { dengan performa hardware klien }\end{array}$ \\
\hline 4. & $\begin{array}{l}\text { Memilih salah satu } \\
\text { lokasi yang ada pada ITS }\end{array}$ & $\begin{array}{l}\text { Terdapat pilihan lokasi pada peta ITS } \\
\text { untuk dijelajahi }\end{array}$ \\
\hline
\end{tabular}

\section{Pemilihan Tombol Navigasi dan Kontrol}

Pemilihan tombol navigasi merupakan hal yang sangat penting dalam pengoperasian aplikasi tiga dimensi. Untuk itu penulis membuat daftar tombol navigasi yang disesuaikan dengan game tiga dimensi yang beredar pada umumnya. Navigasi yang digunakan mencakup dari berbagai kombinasi keyboard dan mouse komputer untuk mengontrol navigasi dan cara kerja aplikasi.

Tabel 2

Hasil analisa pemilihan tombol navigasi

\begin{tabular}{|c|c|c|c|c|}
\hline No. & Perintah & Tombol & Deskripsi & Analisa \\
\hline 1 & $\begin{array}{l}\text { Bergerak } \\
\text { ke kiri }\end{array}$ & A & $\begin{array}{l}\text { Menggerakkan } \\
\text { karakter ke arah kiri }\end{array}$ & $\begin{array}{l}\text { Umum dipakai } \\
\text { pada game } 3 \\
\text { dimensi }\end{array}$ \\
\hline 2 & $\begin{array}{l}\text { Bergerak } \\
\text { mundur }\end{array}$ & S & $\begin{array}{l}\text { Menggerakkan } \\
\text { karakter ke arah } \\
\text { belakang }\end{array}$ & $\begin{array}{l}\text { Umum dipakai } \\
\text { pada game } 3 \\
\text { dimensi }\end{array}$ \\
\hline 3 & $\begin{array}{l}\text { Bergerak } \\
\text { ke kanan }\end{array}$ & $\mathrm{D}$ & $\begin{array}{l}\text { Menggerakkan } \\
\text { karakter ke arah kanan }\end{array}$ & $\begin{array}{l}\text { Umum dipakai } \\
\text { pada game } 3 \\
\text { dimensi }\end{array}$ \\
\hline 4 & $\begin{array}{l}\text { Bergerak } \\
\text { maju }\end{array}$ & W & $\begin{array}{l}\text { Menggerakkan } \\
\text { karakter158ke arah } \\
\text { depan }\end{array}$ & $\begin{array}{l}\text { Umum dipakai } \\
\text { pada game } 3 \\
\text { dimensi }\end{array}$ \\
\hline 5 & Menoleh & $\begin{array}{l}\text { Pointer } \\
\text { mouse }\end{array}$ & $\begin{array}{lr}\text { Mengubah } & \text { arah } \\
\text { pandang karakter } \\
\text { sesuai pointer mouse }\end{array}$ & $\begin{array}{l}\text { Umum dipakai } \\
\text { pada game } 3 \\
\text { dimensi }\end{array}$ \\
\hline 6 & Melompat & Spasi & $\begin{array}{l}\text { Melakukan gerak } \\
\text { dengan mengangkat } \\
\text { kaki (ke bawah, ke } \\
\text { atas) dengan cepat }\end{array}$ & $\begin{array}{l}\text { Umum dipakai } \\
\text { pada game } 3 \\
\text { dimensi }\end{array}$ \\
\hline 7 & Lari & Shift & $\begin{array}{l}\text { Menambah akselerasi } \\
\text { aktor }\end{array}$ & $\begin{array}{l}\text { Umum dipakai } \\
\text { pada game } 3 \\
\text { dimensi }\end{array}$ \\
\hline 8 & Pause & Esc & $\begin{array}{l}\text { Menu } \\
\text { diaktifkan }\end{array}$ & $\begin{array}{l}\text { Umum dipakai } \\
\text { pada game } 3 \\
\text { dimensi }\end{array}$ \\
\hline
\end{tabular}

\section{HASIL DAN PEMBAHASAN}

\section{A. Hasil pengujian fungsional}

Uji coba fungsional merupakan pengujian aplikasi melalui unit test dari rancangan test case yang dapat dilihat pada lampiran C. Semua scenario pada test case dilakukan dan hasil yang keluar pada aplikasi dibandingkan dengan hasil pada test case. (Tabel 3)
Tabel 3.

Hasil Uji Coba Test Case

\begin{tabular}{cll}
\hline \hline ID test & \multicolumn{1}{c}{ Scenario } & Hasil \\
\hline TC01 & Memilih menu jelajah peta & Berhasil \\
TC02 & Memilih tombol kembali & Berhasil \\
TC03 & Melihat peta 2D & Berhasil \\
TC04 & Navigasi maju & Berhasil \\
TC05 & Navigasi ke kiri & Berhasil \\
TC06 & Navigasi mundur & Berhasil \\
TC07 & Navigasi ke kanan & Berhasil \\
TC08 & Navigasi menambah kecepatan & Berhasil \\
C09 & Navigasi melompat & Berhasil \\
TC10 & Memuat halaman pause menu & Berhasil \\
TC11 & Menutup halaman pause menu & Berhasil \\
TC12 & Menambah kualitas grafik 1 level & Berhasil \\
TC13 & Mengurangi kualitas grafik1 level & Berhasil \\
TC14 & Merubah kualitas grafik & Berhasil \\
TC15 & Kembali ke halaman main meu & Berhasil \\
TC16 & Memilih menu website & Berhasil \\
TC17 & Memilih menu kembali & Berhasil \\
\hline \hline
\end{tabular}

\section{B. Hasil pengujian non fungsional}

Uji coba non-fungsional merupakan pengujian aplikasi yang dijalankan pada beberapa komputer dengan spesifikasi yang berbeda dan membangdingkan performa aplikasi peta 3D.

\section{Uji performa aplikasi}

Uji coba performa dinilai pada FPS (frame per second). Disini penulis menambahkan fitur fps counter pada aplikasi untuk melihat nilai fps aplikasi saat dijalankan. Aplikasi dijalankan melalui editor unity. Pada pengujian fps ini, kualitas grafik aplikasi ditentukan pada level "fastest". Resolusinya diatur pada ukuran $1024 \times 768$.

Tabel 4.

Spesifikasi komputer 1

\begin{tabular}{lll}
\hline \hline \multicolumn{3}{c}{ Spesifikasi } \\
\hline Prosesor & $:$ & $\begin{array}{l}\text { Intel®core } \\
\text { CPUs) }\end{array}$ \\
Memori & $:$ & $4096 \mathrm{MB}$ \\
VGA & $:$ & Nvidia geforce GT X 650Ti (4064 MB) \\
Sistem Operasi & $:$ & Windows 10 pro 64-bit (build 15063) \\
\hline \hline
\end{tabular}

Tabel 5.

Spesifikasi komputer 2

\begin{tabular}{lll}
\hline \hline \multicolumn{2}{c}{ Spesifikasi } \\
\hline Prosesor & $:$ & Intel@core \\
& CPUs) \\
Memori & $:$ & $4096 \mathrm{MB}$ \\
VGA & $:$ & Intel(R) G41 Express Chipset \\
Sistem Operasi & $:$ & Windows 7 pro 64-bit \\
\hline \hline
\end{tabular}

Hasil pengujian rata2 pada aplikasi dapat dilihat pada Tabel 6 .

Hasil pengujian offline 
Tabel 6.

Hasil pengujian offline

\begin{tabular}{lll}
\hline \hline System komputer & Fps rata2 & Keterangan \\
\hline Pc 1 & 32 & Cukup \\
Pc 2 & 10 & Buruk \\
\hline \hline
\end{tabular}

\section{Uji Performa Web}

Pengujian ini ditujukan untuk mengetahui performa aplikas i saat diletakkan ke web serverdan diakses oleh pengguna dalam jaringan local. Uji coba ini dilakukan dengan menjadikan 1 komputer sebagai server dan lainnya menjadi client. Penulis juga melakukan pengujian pada kompabilitas browser. Pada pengujian ini, aplikasi dijalankan pada bermacam-macam browser.

Tabel 7.

Hasil pengujian pada kompabilitas browser

\begin{tabular}{cccc}
\hline \hline Nama browser & Fps & Lama loading & Hasil \\
\hline Mozilla & 32 & 32 & Berhasil \\
firefox & & & \\
MS Edge 12 & 34 & 37 & Berhasil \\
Google & 32 & 31 & Berhasil \\
chrome & & 33 & Berhasil \\
Opera & 33 & - & Gagal \\
Safari & - & - & Gagal \\
Internet & - & & \\
explorer 11 & & & \\
\hline \hline
\end{tabular}

Terdapat beberapa peta 3D yang gagal dijalankan pada web browser yaitu peta bangunan ITS yang sudah dibuat oleh peneliti terdahulu. Hal ini disebabkan pada web browser terbaru sudah tidak mendukung plug-in unity web player. Peta 3D bangunan ITS ters ebut masih dapat dibuka dengan firefox versi 51. Pada google chrome dan opera aplikasi dapat diakses melaui localhost tetapitidak dapat diakses melalui path file. Hal ini disebabkan chrome membatasi skrip yang dibuka melalui file lokal untuk menambah keamanan.

\section{V1. KESIMPULAN}

Berdasarkan hasil penelitian didapatkan beberapa simpulan yang dijelaskan ke dalam beberapa poin berikut ini:
1. Performa rendering sangat dipengaruhi oleh spesifikasi hardware unit komputer. Salah satunya pengaruh GPU (Graphics Processing Unit) merupakan hal yang sangat berperan.

2. Bandwith juga berpengaruh untuk mengakses aplikasi saat diletakkan pada web server. Peran bandwith disini berguna pada proses pengambilan data aplikasi yang selanjutnya akan di-load ke komputer. Jadi, lebih besar bandwith, maka lebih cepat aplikasi diakses.

3. Dalam pengoperasian aplikasi minimum spesifikasi yang disarankan CPU Core2Duo, memory RAM 4 GB, VGA dengan VRAM $2 \mathrm{~GB}$.

4. Dalam pembuatan peta 3D di unity untuk mempermudah adanya update, penulis membagi peta lahan kosong menjadi beberapa bagian. Pembagian ini disesuaikan dengan nama area yang akan dibangun menurut masterplan ITS.

5. Unity dapat menghasilkan aplikasi berbasis website dan dapat dibuka pada beberapa web browser seperti Mozilla firefox, microsoft edge, google chrome.

\section{DAFTAR PUSTAKA}

[1] kbbi.web.id, “Arti kata peta - Kamus Besar Bahasa Indonesia (KBBI) Online.” [Online]. Available: http://kbbi. web.id/peta. [Accessed: 05Aug-2016].

[2] Lh.surabaya.go.id, "Official Website Badan Lingkungan Hidup Pemerintah Kota Surabaya." [Online]. Available: http://h.surabaya.go.id/weblh/?c=main\&m=ecocampus.

[3] F. N. Nugrohoadi, "Pengembangan Peta Tiga Dimensi Interaktif untuk Graha ITS dan UPT Bahasa Institut Teknologi Sepuluh Nopember Menggunakan Unity 3DEngine," Surabaya, 2014.

[4] W.t. f. encyclopedia, "Unity (game engine)." [Online]. Available: https://en.wikipedia.org/wiki/Unity_(game_engine). [Accessed: 29Jul-2016].

[5] Wikipedia bahasa Indonesia, "3 dimensi." [Online]. Available: https://id.wikipedia.org/wiki/3_dimensi. [Accessed: 26-Mar-2016].

[6] Microsoft, "Understanding Frames Per Second (FPS)," 2017. [Online]. Available: https://support.microsoft.com/idid/help/269068/understanding-frames-per-second-fps. [Accessed: 16-Sep-2017]. 